\title{
Differences in Defense Mechanisms and Psychological Characteristics According to Suicide Attempt in Patients with Depression
}

\author{
Jae Hwa Choi, Hye-Geum Kim, Eun-Jin Cheon, Young-Ji Lee, \\ Hee Jung Park, Ji Yean Kim, and Bon-Hoon Koo \\ Department of Psychiatry, College of Medicine, Yeungnam University, Daegu, Korea
}

\author{
우울증 환자에서 자살 시도 유무에 따른 방어기제와 심리적 특성의 차이 \\ 최재화 · 김혜금 · 천은진 · 이영지 · 박희정 · 김지연 · 구본훈 \\ 영남대학교 의과대학 정신건강의학교실
}

\begin{abstract}
Objectives: The objective of the present study was to identify the differences between the defense mechanisms and psychological characteristics implemented by patients who have attempted suicide, and those implemented by depressed patients who have not. Methods: We recruited 250 depressed patients (67 with a history of one or more suicide attempts, and 183 patients without any history of suicide attempts) identified based on diagnostic criteria of the Diagnostic and Statistical Manual of Mental Disorders-IV-text revision. We compared the clinical and psychological characteristics of the two groups using the Symptom Checklist90-Revised (SCL-90-R), the Minnesota Multiphasic Personality Inventory-2 (MMPI-2), the Personality Disorder Questionnaire-4+ (PDQ-4+), and the Defense Style Questionnaire (DSQ). Results: The patients who had a history of suicide attempt(s) recorded higher scores in all subscales of the SCL-90-R (except phobic anxiety), as well as the Infrequency (F), Back Infrequency [F(B)], Hypochondriasis (Hs), Depression (D), Psychopathic deviate (Pd), Paranoia (Pa), Psychasthenia (Pt), Schizophrenia (Sc), Hypomania (Ma) scales of the MMPI than those patients with no history of attempted suicide. The patients with no history of suicide attempt(s) recorded higher scores on the Correction (K), Superlative self-presentation (S) scales of the MMPI than those who had attempted suicide. The incidence of paranoid, schizotypal, avoidant, dependent, depressive and negativistic personality disorders (as assessed by the PDQ criteria) was elevated in those patients with histories of suicide attempt(s). Maladaptive and image-distorting defense style, as assessed by the DSQ, and acting out and affiliation were also greater in those with histories of suicide attempt(s). Conclusion: It appears that depressed patients who attempt suicide experience more clinical symptoms, use primitive defense mechanisms and, apparently, have some predictably characteristic problems. Thus, these findings might be useful to those in clinical practice, for the purpose of evaluating depressed patients at high risk for attempted suicide, versus clinically depressed patients who are not.

Psychoanalysis 2017;28(4):96-106
\end{abstract}

KEY WORDS: Depression · Suicide attempt $\cdot$ Psychological characteristics $\cdot$ Defense mechanisms.

Received: August 1, 2017 Revised: August 22, 2017 Accepted: August 25, 2017

Address for correspondence: Bon-Hoon Koo, MD, PhD

Department of Psychiatry, College of Medicine, Yeungnam University, 170 Hyeonchung-ro, Nam-gu, Daegu 42415, Korea

Tel: +82-53-620-3343, Fax: +82-53-629-0256, E-mail: vijnana@chol.com

\begin{abstract}
서 론
통계청의 사망 원인 통계에 따르면 우리나라의 자살률은 2000년대 들어 가파르게 증가하여 인구 10 만 명당 자살자

This is an Open Access article distributed under the terms of the Creative Commons Attribution Non-Commercial License (http://creativecommons.org/licenses/by-nc/4.0) which permits unrestricted non-commercial use, distribution, and reproduction in any medium, provided the original work is properly cited.
\end{abstract}

수는 2000년 13.6명에서 2015년 26.5명으로 자살률은 약 2배 증가하였으며, 2015년 자살자 수는 총 13,513명으로 전체 사 망 원인 중 5위를 차지하게 되었다(Cho 등 2009; Statistics Korea 2016). 이는 전체 Organization for Economic Cooperation and Development(OECD) 국가 중 가장 높은 수준 으로, 2012 2015년 기준 OECD 국가 표준 인구 10만 명당 자살 인구가 평균 12.0 명인 것에 비하여 두 배 수준이다 (OECD 2015). 대다수 OECD 국가들은 자살 증가율이 꾸준 
히 감소하는 반면 우리나라는 자살 인구와 자살률의 지속적 인 증가로 2003년부터 12년째 OECD 국가 중 자살률 1 위를 지속해왔다(Cho 등 2009). 세계보건기구에 의하면 20번의 자살 기도가 있으면 한 번의 자살이 발생하게 되는데(World Health Organization 2009), 2011년 시행한 전국정신질환실 태 역학조사에 의하면 전 국민의 $3.2 \%$ 가 평생 한 번 이상의 자살 시도를 한 적이 있는 것으로 나타났다(Seoul National University College of Medicine 2012).

자살을 이끄는 가장 위험한 단일 요인으로 우울이 제시되 어 왔는데(Brent 등 1993; Lewinsohn 등 1994), 자살 시도를 한 경우에 그렇지 않은 일반인보다 평생 동안 주요우울장애 를 경험할 위험이 자살 기도를 1 회 한 경우에는 6.5 배, 2회 이 상 한 경우에는 7.9배 더 높다는 보고가 있다(Cho 등 2009). 우울증 치료를 위해 병원을 방문한 723명을 대상으로 한 국 내의 우울증 코호트 연구에서는 $19.8 \%$ 가 과거 1 회 이상의 자 살 시도를 하였고, 약 $70 \%$ 에서 연구기간 중 자살 생각을 보 고하였다(Kim 등 2011). 또한 핀란드에서 자살 사망자 229 명을 대상으로 한 사후 부검연구에서 주요우울장애가 $59 \%$ 에서 동반되었음이 밝혀졌고(Henriksson 등 1993), 자살 희 생자를 대상으로 한 20개 이상의 심리적 부검 연구에서 자살 시도자의 30 90\%가 우울증을 가지고 있었음이 보고된 바 있다(Isometsä 2001). 이외에도 우울증 환자에서 일반인에 비하여 자살 위험성이 높다는 것에 대한 많은 국내외 기존의 연구들이 있다(Angst 등 2002; Jeon 2011; Kim 등 2010). 게 다가 2016년 정신질환실태조사에 의하면, 우울증의 평생 유 병률과 일년 유병률은 각각 $5.1 \%, 1.5 \%$ 로 지난 1년 간 우울증 을 경험한 인구는 61만 명으로 추산되며(Korean Ministry of Health and Welfare와 Samsung Medical Center 2017), 이는 결 코 적은 수가 아님을 생각할 때 우울증 및 자살 문제의 심각성 은 더 크다고 할 수 있다.

우울증이 자살의 가장 큰 원인 중 하나임은 논란의 여지 가 없으나 기존의 연구들은 우울증의 생물학적 원인에 초점 을 맞추어 자살과 우울증의 연관성을 설명하거나 이 둘의 역학 연구에 관한 것들이고, 특징적인 방어기제를 비롯한 심 리적 특성에 관한 연구는 많지 않다. 우울 증상의 심각도보 다 그 증상에 대한 개인의 대처방식(coping strategies)이 자 살 시도에 더 큰 영향을 줄 수 있다(Hovanesian 등 2009). 여 기서 대처방식이란 개인이 스트레스에 대해 어떻게 반응하 는지를 일컫는 것으로, 정신역동적 이론의 용어로는 방어기 제(defense mechanism)를 말한다(Corruble 등 2004). 우울 증 환자에서 특정한 방어기제를 비롯한 심리적 특성이 자살 시도와 관련성이 있는지를 알아보기 위한 선행연구가 있다. Corruble 등(2004)은 156 명의 우울증 환자들을 대상으로 한
연구에서 일생 동안의 자살 시도 횟수가 미성숙한(immature) 방어유형과 신경증적(neurotic) 방어유형 모두와 연관성이 있 다고 하였다. Hovanesian 등(2009)이 75명의 우울증 환자를 대조군, 자살 사고는 있으나 시도는 하지 않은 군, 자살 시도 군의 세 군으로 나누어 시행한 연구에서 자살 시도군이 대 조군을 포함한 자살 비시도군보다 표상왜곡(image distorting) 방어유형을 많이 사용하였다. 과거의 연구들에서 우울 증 환자들 중 자살 시도군의 특징으로 세부 방어기제에서 약간의 차이는 있으나 대체로 낮은 수준의 방어유형을 사용 하는 것을 공통적으로 보고하였다. 하지만, 기존의 연구들은 연구 대상자의 수가 상대적으로 적은 것이 제한점이었다. 또 한 기존의 연구들에서는 한 개의 질환이 아닌 다양한 정신 과적 질환을 가진 환자를 대상으로 자살 시도 위험성과 방 어유형 간의 상관성을 알아보기 위한 연구를 시행하여 그 결과에는 모순되는 점들이 있었다(Corruble 등 2004). 또한, 우울증 환자에서의 자살 시도 및 방어유형에 관한 기존의 연구들에서 인격 장애의 유무에 따라 그 특성을 살펴 본 연 구는 없었다. 특히 국내에서는 우울증 환자만을 대상으로 자 살 시도와 연관된 심리적 특성이나 방어기제를 살펴본 연구 는 아직 없었다.

이 연구의 목적은 우울증 환자들 중에서 자살 시도군과 자살 비시도군 사이의 임상 증상에서와 방어기제를 비롯한 심리적 특성, 그리고 인격적 특성에서의 차이를 알아보는 데 있다. 특히, 본 연구에서는 기존 연구들의 제한점을 보완하 여 좀 더 많은 환자들을 대상으로 인격 장애 동반 유무까지 확인을 하여 연구를 시행하였다. 그러한 특성들을 통해 우울 증 환자들의 자살에 영향을 주는 심리적 인자들에는 무엇이 있는지에 대해 고찰해보고자 한다.

\section{방 법}

\section{대 상}

2006년 10월부터 2016년 12월까지 광역시 소재 일 대학병 원 정신건강의학과 병동에 입원하거나 외래를 방문한 18 70 세의 환자 중 본 연구에 필요한 심리검사를 자발적으로 시행 했던 환자들을 대상으로, 이들 중 Diagnostic and Statistical Manual of Mental Disorders-fourth edition-text revision (DSM-IV-TR) 진단기준에 의해 우울장애로 진단된 환자 405 명을 대상으로 하였다. 환자의 정신건강의학과적 진단은 $\mathrm{DSM}-\mathrm{IV}-\mathrm{TR}$ 의 기술적 진단에 따라 정신건강의학과 전문의 에 의해 이루어졌다. 이 중 축 I에 명백한 동반 질환이 있는 경우는 제외하였고, 감별이 필요한 것으로 기록되어 있는 경 우에는 연구자 회의에서 검토 후 우울장애가 주요 진단이며 
감별 진단이 명확하지 않은 경우 본 연구에 포함하였다. 축 II 에 성격장애를 진단받은 경우는 연구 대상자에 포함하였으나 정신지체, 광범위 발달장애 등 다른 축 II의 진단이 동반된 경우는 제외하였다. 또한 심각한 내과, 외과적 질환을 동반 한 경우와, 정신건강의학과적 질환이 기질적 원인에 의한 것 이거나 약물 사용에 의한 것이라고 판단되는 경우 연구 대상 자에서 제외하였다. 연구 대상자의 선정은 본 연구에 포함된 연구자들(정신건강의학과 전문의 3인, 정신건강의학과 전공 의 3인, 임상 심리사 2인)이 소속된 연구자 회의에서 선정하 였다. 환자의 의무기록 및 심리검사 결과를 바탕으로 연구 대상자의 포함기준 및 배제기준을 근거로 하여 진단 및 대상 선정에 대해 심도 있는 회의를 거쳐 연구 대상자를 선정하였 다. 이러한 과정을 통해 전체 우울장애 환자 405명 중 자살 시도군은 67명, 자살 비시도군은 183명을 선정하였다.

\section{방 법}

본 연구는 후향적 연구방법을 사용하였으며, 대상자의 병 록지를 근거로 자료를 수집하였다. 대상 환자들의 기초적인 인구학적 자료, 공존 질환 조사, 자살 시도 횟수 및 방법, 생활 사건(iife stress) 등의 병력 및 본 연구를 수행하는 데 필요한 제반 임상적 자료 등이 사전에 준비한 자료 조사표에 포함되 도록 하였다. 본 연구는 환자 동의서 면제 사유에 속하는 후 향적 연구이므로 환자 동의서는 따로 받지 않았고, 교신저자 가 속해 있는 대학병원 임상연구윤리위원회(Institutional Review Board)의 승인을 받았다(2015-12-020).

\section{도 구}

간이 정신진단검사-90-개정판(The Symptom Checklist90-Revised, SCL-90-R)

Symptom Checklist-90-Revised(SCL-90-R)는 Derogatis 등(1973)이 정신과 환자의 증상을 포괄적으로 선별하기 위해 제작한 자기보고식 다차원 증상목록검사로서 국내에서는 $\mathrm{Kim}$ 등(1984)이 표준화하였다. 채점되지 않는 부가적 문항 을 포함하여 90개의 문항으로 구성되어 있으며 신체화(somatization), 강박증(obsessive-compulsive), 대인민감성(interpersonal sensitivity), 우울(depression), 불안(anxiety), 적 대감(hostility), 공포불안(phobic anxiety), 편집증(paranoid ideation), 정신증(psychoticism)의 9개 증상 차원을 측정한 다. 전체증상지수(general symptom index)는 각 문항에서 1 점 이상에 평정한 점수의 합계를 총 문항 수로 나눈 점수로 현재 장애의 수준 혹은 심도를 나타내며 표출증상합계(Positive Symptom Total, PST)는 증상의 수, 즉 1점 이상에 평정
된 문항 수의 합이다. 표출증상심도지수(Positive Symptom Distress Level)는 각 문항에서 1점 이상에 평정한 점수의 합 계를 1점 이상에 평정된 문항 수(PST)로 나눈 점수이며 이를 통해 순수한 장애의 강도를 알 수 있다.

미네소타 다면적 인성검사(The Minnesota Multiphasic

\section{Personality Inventory-2, MMPI-2)}

Minnesota Multiphasic Personality Inventory(MMPI)는 1943년 Hathaway와 Mckniley에 의해 처음 개발되었고 566 문항으로 구성되었다. 1989년에 개정된 MMPI-2는 총 567 문항으로 9 개의 타당도 척도, 10 개의 임상 척도, 15 개의 내용 척도, 15 개의 보충 척도, 9 개의 재구성 임상 척도, 인격 병리 5 요인 척도, 그 밖에 임상 척도와 내용 척도의 하위 척도들로 구성되어 있다. 본 연구에서는 자실 시도군과 자살 비시도군 간의 심리적 특성의 차이를 파악하기 위해 개정한 MMPI-2 를 사용하였고 이 중 9 개의 타당도 척도와 10 개의 임상 척도 만을 선별적으로 분석에 이용하였다. 각 하위 척도의 특성을 살펴보면, 우선 타당도 척도(validity scales)는 무선반응비일 관성 척도(Variable Response Inconsistency), 고정반응비일 관성 척도(True Response Inconsistency), 비전형 척도(Infrequency, F), 비전형 후반부 척도[Back Infrequency, $\mathrm{F}(\mathrm{B})$ ], 비전형 정신병리 척도[Infrequency Psychopathology, $\mathrm{F}(\mathrm{P})$ ], 부정왜곡 척도(Fake Bad, FBS), 부인 척도(Lie, L), 교정 척 도(Correction, K), 과장된자기제시 척도(Superlative SelfPresentation, S)로 구성되어 있다. 이 척도들은 문항에 대한 반응의 일관성을 확인하고 자신의 문제를 확대 혹은 축소해 서 응답하려는 경향을 파악하여 검사 결과의 신뢰도를 판단 하는 데 그 목적이 있다. 다음으로 임상 척도(clinical scales)는 건강염려증(Hypochondriasis, Hs), 우울증(Depression, D), 히 스테리(Hysteria, Hy), 반사회성(Psychopathic deviate, Pd), 남성-여성특성(Masculinity-femininity, Mf), 편집증(Para-

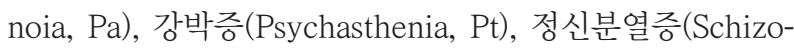
phrenia, $\mathrm{Sc}$ ), 경조증(Hypomania, Ma), 사회적 내향성(Social introversion, $\mathrm{Si}$ )으로 구성되어 있다. 임상 척도는 정신과적 증상의 양상과 심각도, 개인의 인격적 특성을 확인하는 데 사 용되고 있다.

\section{한국판 인격장애 검사(The Personality Disorder Questionnaire-4+, PDQ-4+)}

Personality Disorder Questionnaire-4+(PDQ-4+)는 DSM$\mathrm{IV}$ 의 진단 기준에 맞게 개발되어 10 개의 인격장애를 평가할 수 있는 자기보고형 검사다. 본 연구에는 Kim 등(2000)이 번 안하여 표준화한 것이 사용되었는데, 여기에는 DSM-IV의 
부록에 포함된 부정적 또는 수동-공격성 인격장애와 우울성 인격장애의 진단이 추가되었다. 총 99개의 문항으로 구성되 어 있으며 추가된 인격장애를 포함한 12 개의 인격장애를 측 정할 수 있도록 무작위 순서로 배열되어 있다. 문항 전체가 진 위형(예/아니오)이며 “예”라고 답하는 것이 병적 반응을 의미 한다. 자신의 문제를 축소해서 기록하는 것을 방지하기 위한 질문이 4 개 있고 거짓말을 하거나 성의 있게 대답하지 않은 것을 알아낼 수 있는 질문이 2개 포함되어 있다. 채점 방법은 “너무 좋음(4문항)"과 “응답이 의심스러움(2문항)"을 제외한 93문항에 대해 “예”라는 대답이 있으면 병적 반응으로 1문항 당 1점씩으로 계산한다. 총점이 30점 이상이면 인격장애가 있는 것을 의미하고 정상인들은 대개 20점 이하이다. 따라서 총점이 높을수록 전반적으로 인격장애를 의미한다. 12 개의 인격장애는 각각의 장애에 따라서 최소한 3점 내지 5점 이상 일때 인격장애를 의미한다(Kim 등 2003).

\section{방어유형 설문지(Defense Style Questionnaire, DSQ)}

Defense Style Questionnaire(DSQ)은 Bond와 Vaillant (1986)에 의해 제작된 자기보고식 방어기제 검사 도구로 다 양한 방어기제의 의식적 파생물을 기술하는 78 개 문항과 11 개의 허위성 문항으로 구성되어 있다. $\mathrm{DSQ}$ 는 적절한 타당도 와 재검사 신뢰도를 보유하며, 역동적 인격 이론의 연구에 광 범위하게 사용되고 있다. 방어유형(defense style)은 여러 개 의 방어기제(defense)들로 구성되고, 방어의 성숙도에 따라 서 4가지 방어기제의 양상; 비적응형, 표상왜곡형, 희생형, 적 응형 방어유형을 측정하며, 또한 전치, 투사 등과 같은 구체적 인 방어기제들도 측정할 수 있다. 피검자가 일치하는 정도에 따라 1(일치하지 않음)부터 9(전적으로 일치함)까지의 숫자 로 평정하도록 되어 있다(Chung 등 1993).

\section{통계 분석}

병록지 조사를 통해 얻어진 자료는 IBM SPSS version 23.0(IBM Co, Armonk, NY, USA)을 이용하여 처리하였고, $\mathrm{p}$ 값이 0.05 미만인 경우에 유의성이 있는 것으로 판단하였다. 통계 분석은 우울증 환자에서 자살을 시도하지 않은 군과 시 도한 군 사이의 SCL-90-R, MMPI-2, PDQ-4+, DSQ에서 어떠한 차이가 있는지 알아보기 위해 나이와 성별을 통제하 여 다변량 분석을 시행하였다. 자살 시도에 영향을 미치는 인격장애의 유무를 포함한 임상적 변인 및 심리적 특성을 알 아보기 위해 이분형 로지스틱 회귀분석를 시행하였다.

\section{결 과}

\section{인구학적 및 임상적 특성}

연구 대상자는 자살 시도군 67 명, 자살 비시도군 183 명이 었고, 임상연구윤리위원회로부터 승인 받은 연구 대상자의 임상적 자료 수집 기간인 2006년 10월부터 2016년 12월까지 의 기간 동안 자살로 인한 사망자는 없었다. 자살 시도군 67 명 중 45명이 1 번, 12 명이 2 번의 자살 시도를 보고하였으며, 10 명이 3 번 이상의 자살 시도를 보고하였다. 자살 시도 방법 에 대한 조사에서 67 명 중 9명이 미응답하였고, 2 개 이상의 자살 시도 방법을 동시에 사용한 사람은 5 명이었다. 음독이 24명으로 가장 많았고, 도구 사용이 19명, 목맴이 10명, 투신 이 6 명, 기타 1 명으로 조사되었다. 연구 대상자의 성별은 남 성이 96명(38.4\%), 여성이 154명(61.6\%)이었고, 나이와 성 별, 성격장애의 동반 유무에서 두 집단 간 유의한 차이가 있 었다. 그 외 결혼 상태, 교육 정도, 생활 사건의 유무에서는 두 집단 간 유의한 차이는 없었다(Table 1).

\section{심리적 특성 및 방어기제}

\section{$\mathrm{SCL}-90-\mathrm{R}$ 점수비교}

SCL-90-R의 공포불안 척도를 제외한 8개의 모든 증상차 원에서 자살 시도군이 자살 비시도군보다 유의하게 높았다. 신체화 척도, 강박증 척도에서 자살 시도군이 자살 비시도군 보다 유의하게 높았고 $(\mathrm{p}<0.05)$, 대인 민감성 척도, 우울 척 도, 적대감 척도, 표출증상합계, 표출증상심도지수에서 자살 시도군이 자살 비시도군에 비해 유의하게 높았다 $(\mathrm{p}<0.01)$. 그리고 불안 척도, 편집증 척도, 정신증 척도, 전체증상지수에 서도 자살 시도군이 자살 비시도군에 비해 유의하게 높았다 $(\mathrm{p}<0.001)$ (Table 2).

\section{MMPI-2 점수비교}

타당도 척도 중 비전형 척도(F)에서 자살 시도군이 자살 비 시도군에 비해 유의하게 높았고 $(\mathrm{p}<0.05)$, 비전형 후반부 척 도 $[\mathrm{F}(\mathrm{B})]$ 에서도 자살 시도군이 자살 비시도군에 비해 유의하 게 높았다 $(\mathrm{p}<0.01)$. 교정 $(\mathrm{K})$ 척도에서 자살 비시도군이 자살 시도군에 비해 유의하게 높았고 $(\mathrm{p}<0.05)$, 과장된 자기제시 $(\mathrm{S})$ 척도에서도 자살 비시도군이 자살 시도군에 비해 유의하게 높았다 $(\mathrm{p}<0.01)$. 임상 척도 중 건강염려증 $(\mathrm{Hs})$ 척도, 우울증 (D) 척도에서 자살 시도군이 자살 비시도군보다 유의하게 높 았고 $(\mathrm{p}<0.05)$, 반사회성 $(\mathrm{Pd})$ 척도, 편집증 $(\mathrm{Pa})$ 척도, 강박증 $(\mathrm{Pt})$ 척도, 정신분열증 $(\mathrm{Sc})$ 척도, 경조증 $(\mathrm{Ma})$ 척도에서 자살 시 도군이 자살 비시도군에 비해 유의하게 높았다 $(\mathrm{p}<0.01)(\mathrm{Ta}-$ 
Table 1. Demographic and clinical characteristics of the patients with no suicide attempt and suicide attempt

\begin{tabular}{|c|c|c|c|c|c|}
\hline Variables & $\begin{array}{c}\text { NSA }(n=183) \\
n(\%)\end{array}$ & $\begin{array}{c}\text { SA }(n=67) \\
n(\%)\end{array}$ & $\begin{array}{c}\text { Total }(n=250) \\
n(\%)\end{array}$ & $\chi^{2}$ or $\mathrm{t}$ & p-value \\
\hline Age (mean \pm SD) & $40.11 \pm 14.88$ & $33.47 \pm 11.89$ & $38.34 \pm 14.42$ & -3.645 & $<0.001$ \\
\hline Gender & & & & 3.902 & 0.048 \\
\hline Male & $77(42.1)$ & $19(28.4)$ & $96(38.4)$ & & \\
\hline Female & $106(57.9)$ & $48(71.6)$ & $154(61.6)$ & & \\
\hline Marital status & & & & 7.568 & 0.056 \\
\hline Unmarried & $54(29.5)$ & $30(44.8)$ & $84(33.6)$ & & \\
\hline Married, digamy & $95(51.9)$ & $28(41.8)$ & $123(49.2)$ & & \\
\hline Divorce, separation & $14(7.7)$ & $1(1.5)$ & $15(6.0)$ & & \\
\hline None response & $20(10.9)$ & 8 (11.9) & $28(11.2)$ & & \\
\hline Academic background & & & & 7.134 & 0.211 \\
\hline Elementary school & $74(40.4)$ & $19(28.4)$ & $93(37.2)$ & & \\
\hline Middle school & $10(5.5)$ & $7(10.4)$ & $17(6.8)$ & & \\
\hline High school & $27(18.8)$ & $10(14.9)$ & $37(14.8)$ & & \\
\hline University & $29(15.8)$ & $12(17.9)$ & $41(16.4)$ & & \\
\hline Graduate school & $3(1.6)$ & $4(6.0)$ & $7(2.8)$ & & \\
\hline None response & $40(21.9)$ & $15(22.4)$ & $55(22.0)$ & & \\
\hline Life events & & & & 0.002 & 0.964 \\
\hline No & $88(48.2)$ & $32(47.8)$ & $120(48.0)$ & & \\
\hline Yes & $32(47.8)$ & $35(52.2)$ & $130(52.0)$ & & \\
\hline Bereavement & $8(4.4)$ & $2(3.0)$ & $10(4.0)$ & & \\
\hline Disease & $21(11.5)$ & $5(7.5)$ & $26(10.4)$ & & \\
\hline Disease of family member (not patient's own) & $8(4.4)$ & $0(0.0)$ & $8(3.2)$ & & \\
\hline Accident of patient's own & $4(2.2)$ & $0(0.0)$ & $4(1.6)$ & & \\
\hline Accident of family member (not patient's own) & $4(2.2)$ & $0(0.0)$ & $4(1.6)$ & & \\
\hline Couple conflict & $39(21.3)$ & $18(26.9)$ & $57(22.8)$ & & \\
\hline Conflict not between couple & $51(27.9)$ & $25(37.3)$ & $76(30.4)$ & & \\
\hline Interpersonal conflict not in family & $27(14.8)$ & $14(20.9)$ & $41(16.4)$ & & \\
\hline Economic problem & $26(14.2)$ & $9(13.4)$ & $35(14.0)$ & & \\
\hline Occupational problem & $24(13.1)$ & $13(19.4)$ & $37(14.8)$ & & \\
\hline Legal problem & $5(2.7)$ & $1(1.5)$ & $6(2.4)$ & & \\
\hline Etc & $11(6.0)$ & $4(6.0)$ & $15(6.0)$ & & \\
\hline Personality disorder & & & & 21.816 & $<0.001$ \\
\hline No & $118(64.5)$ & $21(31.3)$ & $183(55.6)$ & & \\
\hline Yes & $65(35.5)$ & $46(68.7)$ & $111(44.4)$ & & \\
\hline
\end{tabular}

SD: standard deviation, NSA: non suicide attempter, SA: suicide attempter

ble 3, Figure 1).

\section{$\mathrm{PDQ}-4+$ 점수비교}

인격장애별 소척도 중 편집성 인격장애 척도, 분열형 인격 장애 척도, 회피성 인격장애 척도, 의존성 인격장애 척도, 그 리고 부정적 인격장애 척도에서 자살 시도군이 자살 비시도 군에 비해 유의하게 높았다 $(\mathrm{p}<0.05)$. 그리고 우울성 인격장애 척도에서 자살 시도군이 자살 비시도군에 비해 유의하게 높 았다 $(\mathrm{p}<0.01)$. 그 외 인격장애별 소척도에서는 두 군 간의 유의한 차이가 없었다(Table 4).
$\mathrm{DSQ}$ 점수비교

4가지 방어유형 중 비적응형 방어유형과 표상왜곡형 방어 유형에서 자살 시도군이 자살 비시도군에 비해 유의하게 높 았다 $(\mathrm{p}<0.01)$. 개별 방어기제에서는 행동화(acting out)와 친 화(affiliation)에서 자살 시도군이 자살 비시도군에 비해 유 의하게 높았다 $(\mathrm{p}<0.05)$ (Table 5).

\section{자살 시도군에서 임상변인 및 심리척도의 회귀분석 결과}

자살 시도군과 자살 비시도군에서 임상변인 및 심리척도 에 대한 이항 로지스틱 회귀분석 결과 경조증 척도 $(\mathrm{p}<0.05)$ 
Table 2. Comparisons of the scores of SCL-90-R in the patients with no suicide attempt and suicide attempt

\begin{tabular}{lccrr}
\hline \multicolumn{1}{c}{ Variables } & $\begin{array}{c}\text { NSA }(\mathrm{n}=183) \\
\text { mean } \pm \text { SD }\end{array}$ & $\begin{array}{r}\text { SA }(\mathrm{n}=67) \\
\text { mean } \pm \text { SD }\end{array}$ & F & p-value \\
\hline Somatization & $1.19 \pm 0.83$ & $1.52 \pm 0.83$ & 5.259 & 0.023 \\
Obsessive-compulsive & $1.71 \pm 0.83$ & $2.09 \pm 0.79$ & 6.498 & 0.011 \\
Interpersonal sensitivity & $1.39 \pm 0.85$ & $1.91 \pm 0.91$ & 11.377 & 0.001 \\
Depression & $1.90 \pm 0.91$ & $2.44 \pm 0.87$ & 11.399 & 0.001 \\
Anxiety & $1.37 \pm 0.89$ & $1.95 \pm 0.96$ & 13.209 & $<0.001$ \\
Hostility & $1.11 \pm 0.96$ & $1.72 \pm 1.04$ & 11.320 & 0.001 \\
Phobic anxiety & $0.85 \pm 0.84$ & $1.14 \pm 0.80$ & 2.781 & 0.097 \\
Paranoid ideation & $0.99 \pm 0.87$ & $1.57 \pm 1.01$ & 14.270 & $<0.001$ \\
Psychoticism & $1.07 \pm 0.77$ & $1.56 \pm 0.84$ & 12.494 & $<0.001$ \\
General symptom index & $1.36 \pm 0.73$ & $1.83 \pm 0.73$ & 13.636 & $<0.001$ \\
Positive symptom total & $58.41 \pm 19.56$ & $69.59 \pm 14.76$ & 11.754 & 0.001 \\
Positive symptom distress level & $1.99 \pm 0.62$ & $2.30 \pm 0.65$ & 8.121 & 0.005 \\
\hline SCL-90R: Symptom
\end{tabular}

SCL-90-R: Symptom Checklist-90-Revised, SD: standard deviation, NSA: non suicide attempter, SA: suicide attempter

Table 3. Comparisons of the scores of MMPI-2 in the patients with no suicide attempt and suicide attempt

\begin{tabular}{|c|c|c|c|c|}
\hline Variables & $\begin{array}{c}\mathrm{NSA}(\mathrm{n}=183) \\
\text { mean } \pm \mathrm{SD}\end{array}$ & $\begin{array}{l}\mathrm{SA}(\mathrm{n}=67) \\
\text { mean } \pm \mathrm{SD}\end{array}$ & $\mathrm{F}$ & p-value \\
\hline \multicolumn{5}{|l|}{ Validity scales } \\
\hline VRIN & $44.98 \pm 8.74$ & $44.93 \pm 8.76$ & 0.306 & 0.581 \\
\hline TRIN & $56.07 \pm 5.42$ & $55.96 \pm 5.26$ & 0.050 & 0.823 \\
\hline $\mathrm{F}$ & $53.74 \pm 11.52$ & $58.22 \pm 10.82$ & 5.455 & 0.020 \\
\hline $\mathrm{F}(\mathrm{B})$ & $56.07 \pm 11.81$ & $62.09 \pm 11.33$ & 10.667 & 0.001 \\
\hline $\mathrm{F}(\mathrm{P})$ & $48.26 \pm 9.08$ & $50.27 \pm 9.20$ & 1.266 & 0.262 \\
\hline $\mathrm{L}$ & $46.52 \pm 9.75$ & $44.94 \pm 8.58$ & 0.176 & 0.675 \\
\hline $\mathrm{K}$ & $46.61 \pm 9.27$ & $42.48 \pm 8.34$ & 5.963 & 0.015 \\
\hline S & $46.65 \pm 10.34$ & $41.28 \pm 9.59$ & 10.674 & 0.001 \\
\hline \multicolumn{5}{|l|}{ Clinical scales } \\
\hline Hypochondriasis & $57.44 \pm 10.81$ & $60.96 \pm 11.67$ & 5.646 & 0.018 \\
\hline Depression & $67.91 \pm 13.58$ & $70.45 \pm 12.23$ & 4.425 & 0.036 \\
\hline Hysteria & $59.19 \pm 10.38$ & $61.22 \pm 9.02$ & 3.873 & 0.050 \\
\hline Psychopathic deviate & $57.25 \pm 11.88$ & $62.51 \pm 10.85$ & 7.310 & 0.007 \\
\hline Masculinity-femininity & $49.02 \pm 10.17$ & $46.79 \pm 10.62$ & 1.265 & 0.262 \\
\hline Paranoia & $56.58 \pm 14.17$ & $64.78 \pm 15.00$ & 12.139 & 0.001 \\
\hline Psychasthenia & $64.46 \pm 13.26$ & $69.12 \pm 11.32$ & 7.669 & 0.006 \\
\hline Schizophrenia & $57.86 \pm 12.29$ & $64.10 \pm 11.42$ & 10.681 & 0.001 \\
\hline Hypomania & $47.54 \pm 9.89$ & $53.58 \pm 11.25$ & 10.692 & 0.001 \\
\hline Social introversion & $61.37 \pm 13.58$ & $63.90 \pm 12.69$ & 2.067 & 0.152 \\
\hline
\end{tabular}

MMPI: Minnesota Multiphasic Personality Inventory, SD: standard deviation, NSA: non suicide attempter, SA: suicide attempter, VRIN: Variable Response Inconsistency, TRIN: True Response Inconsistency, F: Infrequency, F(B): Back Infrequency, F(P): Infrequency Psychopathology, L: Lie, K: Correction, S: Superlative Self-Presentation

가 자살에 유의하게 영향을 주는 인자로 나타났고 불안 척도, 경계성 인격장애 척도, 희생형 방어유형이 자살에 유의하게 영향을 주는 인자로 나타났다 $(\mathrm{p}<0.01)$. 그리고 인격장애 동반 유무, 표상왜곡형 방어유형과 세부 방어기제 중 투사 항목이 자살에 유의하게 영향을 주는 인자로 나타났다 $(\mathrm{p}<0.001)$ (Table 6, 7).

\section{고 찰}

본 연구는 우울증 환자들 중에서 자살 시도군과 자살 비시 도군 사이에 방어기제를 비롯하여 임상 증상과 심리적 특성, 그리고 인격적 특성에 있어서 어떠한 차이가 있는지 알아보 고자 하였다. 
먼저 연구 대상자들의 인구학적 및 임상적 특성을 살펴보 면, 자살 시도군과 자살 비시도군 사이에 나이와 성별에서 차이가 있었다(Table1). 자살 시도군의 나이가 좀 더 어린 경 향이 있었다. 이는 최근 젊은 층의 자살 및 자살 시도가 증가 한 현실을 반영하는 결과로 통계청의 연간 사망 원인 보고에
따르면 2015년 우리나라 10대에서 30대 인구의 사망원인 1 위가 자살이며 특히 20대는 전체 연령대에서 자살 인구가 가 장 많은 연령대로서 그 수는 인구 10만 명당 41.3명이었다. 또한 미국의 경우에도 2000년 초반 15 24세 사이의 젊은 사 람들의 자살은 지난 30 년간 세 배가 되었고, 이에 미국국립정

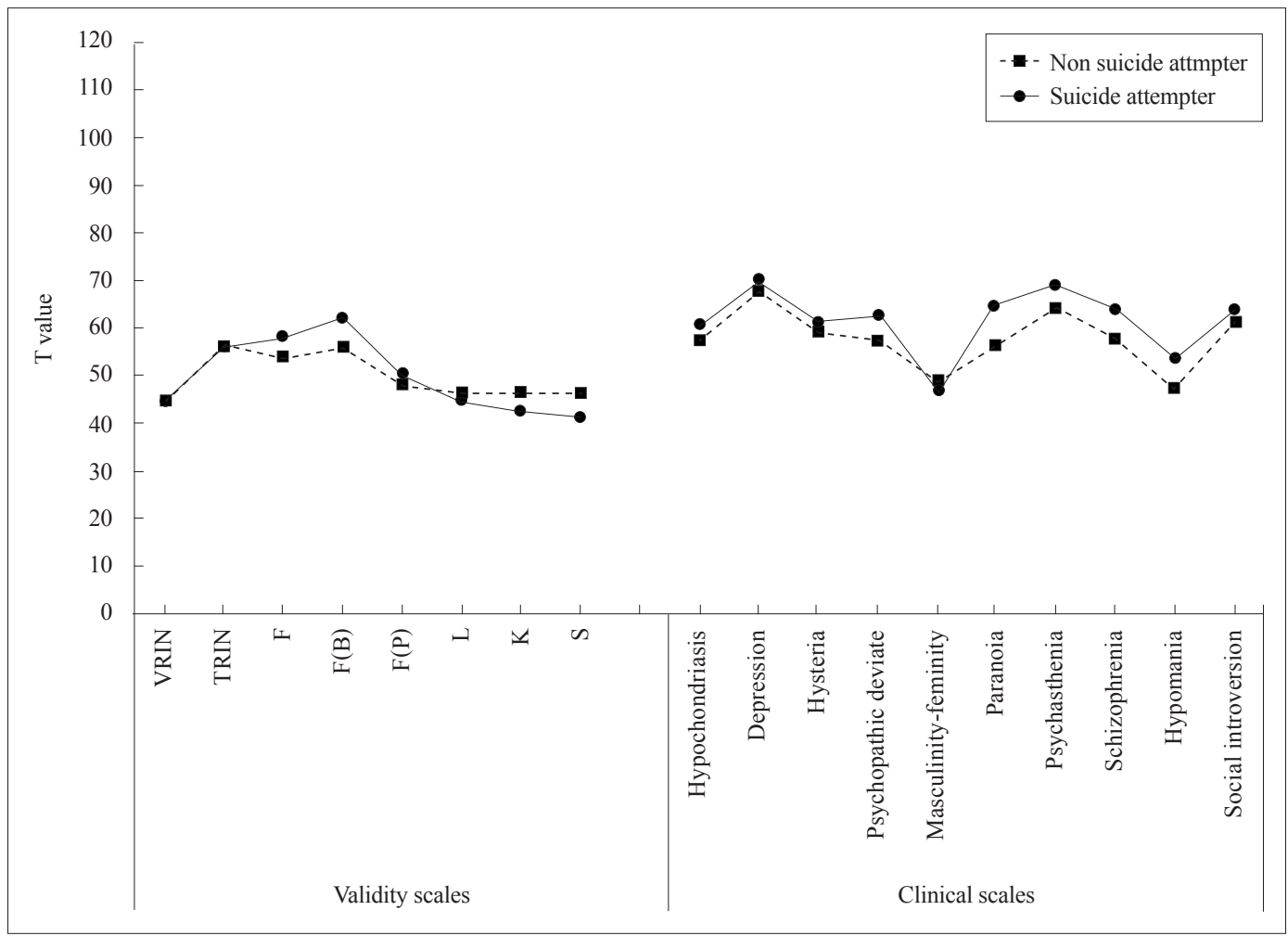

Figure 1. Mean profiles of MMPI-2 in the patients with no suicide attempt and suicide attempt. MMPI: Minnesota Multiphasic Personality Inventory, VRIN: Variable Response Inconsistency, TRIN: True Response Inconsistency, F: Infrequency, $F(B)$ : Infrequency back, $F(P)$ : Infrequency Psychopathology, FBS: Fake Bad Scale, L: Lie, K: Correction, S: Superlative Self-Presentation.

Table 4. Comparisons of the scores of PDQ-4+ in the patients with no suicide attempt and suicide attempt

\begin{tabular}{lcccc}
\hline \multicolumn{1}{c}{ Variables } & $\begin{array}{c}\text { NSA }(\mathrm{n}=183) \\
\text { mean } \pm \text { SD }\end{array}$ & $\begin{array}{c}\text { SA }(\mathrm{n}=67) \\
\text { mean } \pm \text { SD }\end{array}$ & F & palue \\
\hline Paranoid PD & $3.30 \pm 1.70$ & $4.06 \pm 1.67$ & 5.398 & 0.021 \\
Schizoid PD & $3.32 \pm 1.65$ & $3.54 \pm 1.81$ & 0.985 & 0.322 \\
Schizotypal PD & $3.40 \pm 2.04$ & $4.19 \pm 1.90$ & 5.404 & 0.021 \\
Antisocial PD & $1.42 \pm 1.56$ & $1.75 \pm 1.58$ & 0.257 & 0.613 \\
Borderline PD & $4.11 \pm 1.82$ & $4.46 \pm 1.82$ & 0.313 & 0.577 \\
Histrionic PD & $2.80 \pm 1.62$ & $3.49 \pm 1.97$ & 3.290 & 0.071 \\
Narcissistic PD & $2.80 \pm 1.85$ & $3.30 \pm 2.06$ & 1.861 & 0.174 \\
Avoidant PD & $3.77 \pm 1.98$ & $4.58 \pm 1.94$ & 4.608 & 0.033 \\
Dependent PD & $3.75 \pm 1.87$ & $4.55 \pm 2.09$ & 4.235 & 0.041 \\
Obsessive-compulsive PD & $3.70 \pm 1.80$ & $4.12 \pm 1.67$ & 3.747 & 0.054 \\
Depressive PD & $3.67 \pm 1.76$ & $4.58 \pm 2.00$ & 8.278 & 0.004 \\
Negativistic PD & $2.87 \pm 1.80$ & $3.75 \pm 2.13$ & 4.746 & 0.030 \\
\hline PDQ & & & \\
\hline
\end{tabular}

PDQ-4+: Personality Disorder Questionnaire-4+, PD: personality disorder, SD: standard deviation, NSA: non suicide attempter, SA: suicide attempter 
Table 5. Comparisons of the scores of DSQ in the patients with no suicide attempt and suicide attempt

\begin{tabular}{|c|c|c|c|c|}
\hline Variables & $\begin{array}{c}\mathrm{NSA}(\mathrm{n}=183) \\
\text { mean } \pm \mathrm{SD}\end{array}$ & $\begin{array}{l}\mathrm{SA}(\mathrm{n}=67) \\
\text { mean } \pm \mathrm{SD}\end{array}$ & $\mathrm{F}$ & p-value \\
\hline \multicolumn{5}{|l|}{ Cluster score } \\
\hline Maladaptive action & $4.20 \pm 1.17$ & $4.89 \pm 1.12$ & 11.688 & 0.001 \\
\hline Image-distorting & $3.63 \pm 1.10$ & $4.24 \pm 1.25$ & 9.146 & 0.003 \\
\hline Self-sacrificing & $3.97 \pm 1.39$ & $3.83 \pm 1.47$ & 0.058 & 0.809 \\
\hline Adaptive & $4.24 \pm 1.29$ & $3.93 \pm 1.40$ & 2.854 & 0.092 \\
\hline \multicolumn{5}{|l|}{ Defense mechanism } \\
\hline Neurotic denial & $2.99 \pm 1.81$ & $3.51 \pm 2.01$ & 1.757 & 0.186 \\
\hline Nondelusional projection & $3.64 \pm 1.45$ & $3.43 \pm 1.38$ & 1.815 & 0.179 \\
\hline Passive aggression & $6.54 \pm 2.62$ & $7.19 \pm 2.31$ & 3.375 & 0.067 \\
\hline Acting out & $6.03 \pm 1.95$ & $6.93 \pm 1.56$ & 5.381 & 0.021 \\
\hline Splitting of other's image & $4.10 \pm 2.63$ & $4.26 \pm 2.94$ & 0.001 & 0.981 \\
\hline Projective identification & $5.32 \pm 2.71$ & $4.53 \pm 2.67$ & 2.485 & 0.116 \\
\hline Omnipotence & $5.05 \pm 2.17$ & $5.20 \pm 2.36$ & 0.002 & 0.969 \\
\hline Undoing & $3.05 \pm 2.20$ & $3.55 \pm 2.60$ & 1.584 & 0.209 \\
\hline Affiliation & $3.24 \pm 3.35$ & $4.15 \pm 3.64$ & 6.389 & 0.012 \\
\hline Somatization & $2.81 \pm 2.38$ & $3.28 \pm 2.52$ & 0.914 & 0.340 \\
\hline Hypochondriasis & $2.37 \pm 1.33$ & $2.44 \pm 1.25$ & 0.233 & 0.629 \\
\hline
\end{tabular}

DSQ: Defense Style Questionnaire, SD: standard deviation, NSA: non suicide attempter, SA: suicide attempter

Table 6. Result of binomial logistic regression analysis with clinical characteristics and psychological tests in the patients with suicide attempt

\begin{tabular}{lrrrrrr}
\hline & B & SE & Wald & df & p-value & Exp(B) \\
\hline Personality disorder & -1.647 & 0.370 & 19.820 & 1 & $<0.001$ & 0.193 \\
Anxiety at SCL-90-R & 0.554 & 0.208 & 7.120 & 1 & 0.008 & 1.740 \\
Mania at MMPI-2 & 0.046 & 0.018 & 6.597 & 1 & 0.010 & 1.047 \\
Borderline Personality Disorder at PDQ & -0.408 & 0.125 & 10.640 & 1 & 0.001 & 0.665 \\
Image-distorting at DSQ & 0.975 & 0.240 & 16.552 & 1 & $<0.001$ & 2.650 \\
Self-sacrificing at DSQ & -0.366 & 0.141 & 6.754 & 1 & 0.009 & 0.694 \\
Nondelusional projection & -0.715 & 0.163 & 19.239 & 1 & $<0.001$ & 0.489 \\
Constant & -1.595 & 0.928 & 2.955 & 1 & 0.086 & 0.203 \\
\hline
\end{tabular}

SCL-90-R: Symptom Checklist-90-Revised, MMPI: Minnesota Multiphasic Personality Inventory, PDQ: Personality Disorder Questionnaire, DSQ: Defense Style Questionnaire

Table 7. Result of binomial logistic regression analysis with clinical characteristics and psychological tests in the patients with suicide attempt

\begin{tabular}{|c|c|c|c|c|c|c|}
\hline & B & $\mathrm{SE}$ & Wald & $\mathrm{df}$ & p-value & $\operatorname{Exp}(B)$ \\
\hline Age & -0.023 & 0.013 & 3.235 & 1 & 0.072 & 0.978 \\
\hline Gender & -0.819 & 0.339 & 5.846 & 1 & 0.016 & 0.441 \\
\hline Personality disorder & -1.344 & 0.322 & 17.405 & 1 & $<0.001$ & 0.261 \\
\hline \multicolumn{7}{|l|}{ SCL-90-R } \\
\hline Anxiety & 0.332 & 0.190 & 3.069 & 1 & 0.080 & 1.394 \\
\hline \multicolumn{7}{|l|}{ MMPI-2 } \\
\hline $\mathrm{L}$ & 0.032 & 0.020 & 2.598 & 1 & 0.107 & 1.032 \\
\hline Ma & 0.034 & 0.015 & 4.844 & 1 & 0.028 & 1.035 \\
\hline \multicolumn{7}{|l|}{ DSQ } \\
\hline Maladaptive action & 0.402 & 0.189 & 4.498 & 1 & 0.034 & 1.495 \\
\hline Nondelusional projection & -0.298 & 0.121 & 6.062 & 1 & 0.014 & 0.743 \\
\hline Constant & -4.271 & 1.606 & 7.068 & 1 & 0.008 & 0.014 \\
\hline
\end{tabular}

Cox and Snell' $\mathrm{R}^{2}=0.171$, Nagelkerke $\mathrm{R}^{2}=0.287$. SCL-90-R: Symptom Checklist-90-Revised, MMPI: Minnesota Multiphasic Personality Inventory, L: Lie, Ma: Hypomania, DSQ: Defense Style Questionnaire 
신보건원(National Institute of Mental Health)은 청년 자살 예방을 위한 국가적 전략을 진행하는 등 젊은 층의 자살 예 방을 위해 노력하는 실태와 맥락을 같이 하는 결과다(Jeon 등 2004). 성별에 있어서는 자살 시도군에서 여성의 비율이 유의하게 높았으며, 이는 기존의 자살 연구에서 지적되었던 현상인, 전 세계적으로 자살 사망자는 남자에서 더 높으나 자 살 기도가 남자보다는 여자에게서 높다는 사실과 일관되는 결과다(Jeon 등 2010).

생활 사건에서 자살 시도군과 자살 비시도군 간의 유의한 차이가 없었는데, 이는 스트레스가 높은 생활 사건을 경험할 때 사람들은 자살과 관련된 행위를 더 많이 시도하는 경향 이 있다는 기존의 연구들과는 일관되지 않은 결과였다 (Brent 등 1993; Gould 등 1996). 그러나 기존의 연구에서 지 적했듯이 스트레스 상황 하에서 자살을 시도하는 사람도 있 으나 자살을 시도하지 않는 사람들 또한 존재한다(Wang 등 2007). 이는 생활 사건으로 인한 스트레스가 직접적으로 자살 시도를 유도한다기보다는 이에 대처하는 개인의 방식이 자 살을 시도하는지의 여부에 영향을 미칠 수 있음을 시사한다. 스트레스에 대처하는 개인의 방식이란 결국 심리적 방어기 제라고 할 수 있으며, 인격장애 환자들이 그 분류별로 주로 사용하는 심리적 방어기제에 관해서는 이전부터 연구들이 있어 왔다(Bond 2004; Kim 등 2014). 자살과 자살 시도가 인 격 장애와 연관될 수 있다는 연구들이 있으며(Nordström 등 1996; Soloff 등 2000; Statham 등 1998), 본 연구에서도 우울 증 환자들에서 인격장애가 동반되는 경우가 그렇지 않은 경 우에 비하여 자살 시도를 유의하게 더 많이 하였다. 또한 이 러한 결과는 적어도 한 개의 축 II 진단이 있을 시, 그것이 자 살에의 독립적인 위험 인자가 될 수 있다는 기존의 연구와 도 일관되는 결과다(Foster 등 1999).

SCL-90-R의 결과에 있어서, 자살 시도군과 자살 비시도 군 사이에 공포불안 척도를 제외한 전 영역에서 유의한 차이 가 있었다(Table 2). 이로써 자살 시도군이 자살 비시도군에 비하여 훨씬 다양한 여러 가지 임상적 증상을 겪고 있고, 표 출증상합계(PST)와 표출증상심도지수(Positive Symptom Distress Level)에서도 두 군 간 차이가 있는 것으로 보아 자 살 시도군이 자살 비시도군에 비하여 더욱 심한 증상을 겪고 있다고 추정할 수 있다. 이는 자살로 사망한 군과 자살 시도 군이 대조군에 비하여 더 심각한 정신과적 과거력을 가지고 있다는 기존의 후향적 연구와 그 맥락을 같이 한다(Serin 등 2002).

MMPI-2의 전체적인 프로파일을 살펴보면 타당도 척도 중 비전형 척도 $(\mathrm{F})$ 와 비전형 후반부 척도 $[\mathrm{F}(\mathrm{B})]$ 에서 자살 시 도군이 자살 비시도군에 비해 유의하게 높았는데, 이를 통해
자살 시도군이 자살 비시도군에 비해 훨씬 많은 불편감을 느끼고 있다고 추정할 수 있다. 교정 $(\mathrm{K})$ 척도에서 자살 비시 도군이 자살 시도군보다 유의하게 높은 점수를 보인 것은 자살 시도군의 낮은 자아 강도가 반영된 결과로 생각된다. 또한 과장된 자기제시(S) 척도에서도 자살 비시도군이 자살 시도군보다 유의하게 높은 점수를 보였는데, 이는 자살 비시 도군이 자살 시도군보다 긍정적으로 보이려 하는 경향(faking good)이 반영된 것으로 생각된다. 전체적으로 볼 때 자살 시도군이 자살 비시도군보다 좀 더 도움을 요청하는(crying for help) 프로파일을 보이는 것으로 추정된다. MMPI-2 소 항목에서 집단 간 유의한 차이를 보인 임상 척도를 살펴보면 건강염려증 $(\mathrm{Hs})$ 척도, 우울증 $(\mathrm{D})$ 척도, 반사회성 $(\mathrm{Pd})$ 척도, 편집증 $(\mathrm{Pa})$ 척도, 강박증 $(\mathrm{Pt})$ 척도, 정신분열증 $(\mathrm{Sc})$ 척도, 경 조증 $(\mathrm{Ma})$ 척도에서 자살 시도군이 자살 비시도군보다 유의 하게 높았다. 이로써 자살 시도군이 자살 비시도군에 비하여 건강에 대한 염려가 많고 우울한 경향이 있으며, 좀 더 충동 적이고 편집적인 경향, 그리고 강박적인 경향으로 인해 걱정 이 많아 쉽게 소진(burn out)되는 특징을 가질 것이라고 유 추할 수 있다. 또한 자살 시도군이 사회적으로 위축되는 경 향과 감정의 기복이 심한 경향을 더 나타낼 것이라고 추정된 다. 본 연구의 결과는 반사회성 $(\mathrm{Pd})$ 척도, 편집증 $(\mathrm{Pa})$ 척도, 그리고 정신분열증 $(\mathrm{Sc})$ 척도에서의 높은 점수가 자살 행동 (suicidal behavior)과 관련이 있다는 기존의 연구 결과들과도 대체로 일치하였다(Clopton 등 1983; Lester 1992). 또한 우울 증 환자에서 충동성이 자살 시도와 큰 연관성이 있음을 지적 한 기존의 연구들과 그 맥락을 같이 한다(Corruble 등 1999; Corruble 등 2003; Roy 등 1989). 특히 청소년에서의 자살 시 도에서 특징적으로 충동성이 보고된다는 기존의 연구들은, 본 연구에서 보여진 젊은 층에서의 자살 시도가 많은 것, 그 리고 MMPI 결과상 유추해 볼 수 있는 연구 대상자들의 다소 높은 충동성을 뒷받침한다고 할 수 있다(Beautrais 등 1999). 다만 이러한 MMPI의 결과가 항상 동일하게 반복되지는 않 는 것에 대한 지적 또한 존재한다(Daigle 2004).

$\mathrm{PDQ}-4+$ 에서는 인격장애별 소척도 중 편집성, 분열형, 회 피성, 의존성, 우울성, 그리고 부정적 인격장애 척도에서 자 살 시도군이 자살 비시도군에 비하여 유의하게 높은 점수를 나타내었다. 이로써 자살 시도군이 자살 비시도군에 비하여 편집적인 경향이 강하고 대인관계에서 의심이 많으며 사회적 으로 위축되는 경향이 강할 것이라 유추할 수 있다. 또한 자 살 시도군이 자살 비시도군보다 의존적이고 우울 경향, 부정 적 경향의 인격을 가질 것이라고 생각된다. Busch 등(2007)은 의존심의 좌절, 상실, 그리고 이것들로 인한 분노 및 공격성 의 내사가 우울증 및 우울증에서의 자살의 정신 역동 중 하나 
라고 언급한 바 있는데, 이는 본 연구의 결과를 뒷받침한다.

$\mathrm{DSQ}$ 에서는 자살 시도군이 자살 비시도군에 비하여 비적 응형 방어유형과 표상왜곡형 방어유형의 사용이 높았다. Johnson 등(1992)은 비적응형 방어유형과 표상왜곡형 방어유 형의 사용이 높을수록 인격장애의 정도가 심할 수 있다고 하 였다. 특히 비적응형 방어유형은 미숙한 수준의 방어유형으 로 거의 모든 유형의 인격장애와 관련이 있다(Bond과 Vaillant 1986). 표상왜곡형 방어유형 또한 인격장애 환자에서 많이 나타나는 방어유형으로서 특히 경계성 인격장애 환자 에서 주로 사용되는 방어유형임이 기존의 연구들을 통해 알 려져 있다(Bond과 Vaillant 1986; Kim 등 2014). 본 연구에 서 연구 대상자들의 세부적인 인격장애 유형까지는 알 수 없 으나 이는 자살 시도군에서 미성숙한 방어유형을 사용한다는 본 연구의 결과와 대체로 일치한다. 이 외에도 Corruble 등 (2003)은 최근 자살 시도를 한 우울증 환자들이 자살 시도를 하지 않은 우울증 환자들에 비하여 미성숙한 방어기제를 사용 한다고 하였고, 주요 우울증 환자들에서 평생 자살 시도 횟수 는 미성숙한 방어유형과 신경증적 방어유형의 사용 모두와 연관성을 가진다고 하였다(Corruble 등 2004). 세부적인 방어 기제는 행동화, 친화에서 두 군간의 유의한 차이가 나타났는 데, 자살 시도군은 우울하거나 불편한 감정을 해결하기 위해 서 공격성과 분노를 표출하기도 하고, 또한 이러한 감정은 대 인관계에서 친밀해지고자 하는 모습으로 나타나기도 하는 것으로 생각된다. 본 연구에서 두 군 간 유의한 차이가 있었 던 세부적인 방어기제는, Corruble 등(2003)이 우울증 환자에 서의 자살 시도 연구에서 자살 시도의 수가 많아질수록 투사, 수동공격성, 신체화, 행동화, 분열, 취소와 같은 세부 방어기 제의 사용이 두드러진다고 한 것과는 일부 차이가 있었다. 이 러한 차이는 본 연구에 그 대상자의 수가 기존의 연구보다 두 배 이상 많고 따라서 좀 더 다양한 인격적 특성을 가진 대상 자들이 포함되었으며 그에 따라 사용하는 세부 방어기제에 의 차이가 있는 것이 아닌가 추정되며, 추후 비슷한 연구를 통해 이러한 결과가 반복되는지 살펴볼 필요가 있겠다.

자살 시도군과 자살 비시도군에서 임상변인 및 심리척도 에 대한 회귀분석 결과, 인격장애 동반 유무, 불안 척도, 경조 증 척도, 경계성 인격장애 척도, 표상왜곡형 방어유형과 희생 형 방어유형 및 세부 방어기제 중 투사 항목이 자살에 유의하 게 영향을 주는 인자로 나타났다. 회귀분석 결과 이러한 인자 들이 자살 시도 유무에 영향을 주는 설명량은 $37.5 \%$ 였다. 그 리고 이러한 인자들은 각각의 집단을 자살 시도군은 $43.3 \%$, 자살 비시도군은 $91.8 \%$, 전체 집단은 $78.7 \%$ 의 정확도로 분류 하였다. 즉, 본 연구에서 이러한 인자들은 자살 시도군을 정확 히 예측하는 것보다는 자살 비시도군을 더 정확하게 예측하
였다. 이것은 자살 비시도군이 자살 시도군에 비해 그 수가 2 배 정도 많아 자살 비시도군의 심리적 특성이 전체 인자들보 다 더 많이 쏠리는 경향으로 인한 것으로 추정된다. 자살 시 도군과 자살 비시도군 간 유의한 차이가 없었던 경계성 인격 장애 척도, 희생형 방어유형과 세부 방어기제 중 투사 항목 이 회귀 분석 결과 두 집단 간 유의한 차이가 있는 것으로 밝 혀졌는데, 이는 통계 과정상 변인들 간 상호 작용의 영향 및 연구 대상자를 일 대학병원에서 모집한 선정 오류(selection bias) 때문인 것으로 추정된다. 하지만 이 세 가지 요인도 비 록 자살 시도군과 자살 비시도군 사이에는 유의한 차이가 없 었으나 회귀 분석 결과를 통해 볼 때 자살 시도에 영향을 주 는 인자로 추정해 볼 수 있다. 결론적으로 우울증 환자에서 자살 시도에 영향을 줄 수 있는 위험 인자로서 특히 인격장애 가 동반되어 있는 경우, 우울증이지만 불안이 심하게 동반되 어 있는 경우, 단순한 우울보다는 감정 기복이 동반되어 있는 경우, 그리고 낮은 수준의 미성숙한 방어 스타일을 사용하는 경우 등이 있겠다. 임상에서 이러한 환자를 볼 경우 자살 시 도 위험성에 보다 세심한 평가가 필요할 것으로 추정된다.

본 연구의 가장 큰 제한점은 후향적 연구라는 점이다. 그러 므로 자살 시도군과 자살 비시도군 간의 차이점이 자살 시도 의 원인인지 또는 결과인지에 대해 확실하게 단정지을 수 없 으며, 향후 전향적 연구가 필요할 것으로 생각된다. 그리고 본 연구는 일 대학병원의 내원 환자를 대상으로 하였으므로 본 연구 결과의 일반화에 있어서 다소 제한점이 있을 수 있 다. 또 다른 제한점으로는 인격장애의 세부적 진단을 구분하 지 않았다는 점, 그리고 심리적 특성을 자기보고식 검사로만 비교했다는 것이다. 향후에는 우울증 환자군에서 동반되는 인격장애의 종류를 세분하여 자살 시도군과 자살 비시도군 의 임상적 특성 및 심리적 특성을 알아보는 것이 필요할 것으 로 생각되며, 자기보고식 검사뿐만 아니라 임상가 보고 등을 통해 정보를 얻을 필요가 있겠다. 이러한 제한점들에도 불구 하고 본 연구는 기존의 연구들보다 상대적으로 많은 수의 환 자를 대상으로 임상 양상, 심리적 특성과 인격적 특성, 그리 고 방어기제를 포함한 정신역동적 측면까지 함께 살펴봄으 로써 우울증 환자들 중 자살 시도 환자들의 심리적 특성을 이 해하는데 도움을 준다는 점에서 그 의의를 찾을 수 있으며, 임상에서 우울증 환자들 중 자살 시도 위험 인자를 추정하는 데 도움이 될 것으로 생각된다.

\section{Conflicts of Interest}

The authors have no financial conflicts of interest.

\section{REFERENCES}

Angst F, Stassen HH, Clayton PJ, Angst J. Mortality of patients with 
mood disorders: follow-up over 34-38 years. J Affect Disord 2002;68: 167-181.

Beautrais AL, Joyce PR, Mulder RT. Personality traits and cognitive styles as risk factors for serious suicide attempts among young people. Suicide Life Threat Behav 1999;29:37-47.

Bond M. Empirical studies of defense style: relationships with psychopathology and change. Harv Rev Psychiatry 2004;12:263-278.

Bond MP, Vaillant JS. An empirical study of the relationship between diagnosis and defense style. Arch Gen Psychiatry 1986;43:285-288.

Brent DA, Perper JA, Moritz G, Allman C, Friend A, Roth C, et al. Psychiatric risk factors for adolescent suicide: a case-control study. J Am Acad Child Adolesc Psychiatry 1993;32:521-529.

Busch FN, Rudden M, Shapiro T. Psychodynamic Treatment of Depression. Washington, DC: American Psychiatric Publishing;2007.

Cho MJ, Chang SM, Hahm BJ, Chung IW, Bae A, Lee YM, et al. Prevalence and correlates of major mental disorders among Korean adults: a 2006 national epidemiologic survey. J Korean Neuropsychiatr Assoc 2009; $48: 143-152$.

Chung MW, Park SH, Kim SH. A preliminary study for the development of a defense style questionnaire adapted for Koreans. J Korean Neuropsychiatr Assoc 1993;32:707-716.

Clopton JR, Post RD, Larde J. Identification of suicide attempters by means of MMPI profiles. J Clin Psychol 1983;39:868-871

Corruble E, Bronnec M, Falissard B, Hardy P. Defense styles in depressed suicide attempters. Psychiatry Clin Neurosci 2004;58:285288.

Corruble E, Damy C, Guelfi JD. Impulsivity: a relevant dimension in depression regarding suicide attempts? J Affect Disord 1999;53:211215.

Corruble E, Hatem N, Damy C, Falissard B, Guelfi JD, Reynaud M, et al. Defense styles, impulsivity and suicide attempts in major depression. Psychopathology 2003;36:279-284.

Daigle M. MMPI inmate profiles: suicide completers, suicide attempters, and non-suicidal controls. Behav Sci Law 2004;22:833-842.

Derogatis LR, Lipman RS, Covi L. SCL-90: an outpatient psychiatric rating scale--preliminary report. Psychopharmacol Bull 1973;9:13-28.

Foster T, Gillespie K, McClelland R, Patterson C. Risk factors for suicide independent of DSM-III-R Axis I disorder. Case-control psychological autopsy study in Northern Ireland. Br J Psychiatry 1999;175: 175-179.

Gould MS, Fisher P, Parides M, Flory M, Shaffer D. Psychosocial risk factors of child and adolescent completed suicide. Arch Gen Psychiatry 1996;53:1155-1162.

Henriksson MM, Aro HM, Marttunen MJ, Heikkinen ME, Isometsä ET, Kuoppasalmi KI, et al. Mental disorders and comorbidity in suicide. Am J Psychiatry 1993;150:935-940.

Hovanesian S, Isakov I, Cervellione KL. Defense mechanisms and suicide risk in major depression. Arch Suicide Res 2009;13:74-86.

Isometsä ET. Psychological autopsy studies--a review. Eur Psychiatry 2001;16:379-385

Jeon HJ. Depression and suicide. J Korean Med Assoc 2011;54:370-375.

Jeon HJ, Lee JY, Lee YM, Hong JP, Won SH, Cho SJ, et al. Lifetime prevalence and correlates of suicidal ideation, plan, and single and multiple attempts in a Korean nationwide study. J Nerv Ment Dis 2010; 198:643-646

Jeon WT, Nam YY, Park JY, Eoh YK, Lee HS. Study on development of suicide prevention policy: foreign national suicide prevention strategy and analysis of domestic activities. Seoul: Ministry of Health Wel- fare;2004. p.1-221.

Johnson JG, Bornstein RF, Krukonis AB. Defense styles as predictors of personality disorder symptomatology. J Personal Disord 1992;6:408416.

Kim DI, Choi MR, Cho EC. The preliminary study of reliability and validity on the Korean version of personality disorder questionnaire-4+ (PDQ-4+). J Korean Neuropsychiatr Assoc 2000;39:525-538.

Kim HG, Jeong J, Cha Y, Choi JH, Cheon EJ, Lee JY, et al. Differences of defense mechanisms and psychological characteristics between the patients with cluster B and C personality disorders of DSM-IV: implication for theory of borderline personality organization. Psychoanalysis 2014;25:13-23.

Kim KI, Kim JH, Won HT. Korean Manual of Symptom Checklist-90revision. Seoul: Jungangjeokseong Publishing;1984.

Kim SW, Bae KY, Kim JM, Kim SY, Yoo JA, Yang SJ, et al. Psychosocial correlates of attempted suicide and attitudes toward suicide. J Korean Neuropsychiatr Assoc 2010;49:367-373

Kim SW, Stewart R, Kim JM, Shin IS, Yoon JS, Jung SW, et al. Relationship between a history of a suicide attempt and treatment outcomes in patients with depression. J Clin Psychopharmacol 2011;31:449-456.

Kim SY, Kwon SM, Cho SN, Kwon DH, Kang BJ, Kim HT. A study on personality disorder of methamphetamine abuse or dependent patients in Korea. J Korean Soc Biol Ther Psychiatry 2003;9:204-212.

Korean Ministry of Health and Welfare, Samsung Medical Center. The survey of mental disorders in Korea 2016. Seoul: Korean Ministry of Health and Welfare;2017.

Lester D. Why people kill themselves: a 1990s summary of research findings on suicidal behavior. 3rd ed. Springfield, IL: Charles C Thomas; 1992.

Lewinsohn PM, Rohde P, Seeley JR. Psychosocial risk factors for future adolescent suicide attempts. J Consult Clin Psychol 1994;62:297-305.

Nordström P, Gustavsson P, Edman G, Asberg M. Temperamental vulnerability and suicide risk after attempted suicide. Suicide Life Threat Behav 1996;26:380-394.

OECD. Health at a glance 2015: OECD indicators. Paris: OECD Publishing;2015. p56-57.

Roy A, De Jong J, Linnoila M. Cerebrospinal fluid monoamine metabolites and suicidal behavior in depressed patients. A 5-year follow-up study. Arch Gen Psychiatry 1989;46:609-612.

Seoul National University College of Medicine. The epidemiological survey of mental disorders in Korea 2011. Seoul: Ministry of Health and Welfare;2012.

Serin RC, Motiuk L, Wichmann C. An examination of suicide attempts among inmates. Forum Correct Res 2002;14:40-42.

Soloff PH, Lynch KG, Kelly TM, Malone KM, Mann JJ. Characteristics of suicide attempts of patients with major depressive episode and borderline personality disorder: a comparative study. Am J Psychiatry 2000;157:601-608

Statham DJ, Heath AC, Madden PA, Bucholz KK, Bierut L, Dinwiddie $\mathrm{SH}$, et al. Suicidal behaviour: an epidemiological and genetic study. Psychol Med 1998;28:839-855.

Statistics Korea. Death statistics in 2015. Daejeon: Statistics Korea;2016.

Wang MC, Lightsey OR, Pietruszka T, Uruk AC, Wells AG. Purpose in life and reasons for living as mediators of the relationship between stress, coping, and suicidal behavior. J Posit Psychol 2007;2:195-204.

World Health Organization. Suicide prevention (SUPRE). Geneva: World Health Organization;2009. 